\title{
APLICAÇÃO DO RESÍDUO DA MINERAÇÃO DO COBRE PARA MELHORIA DO DESEMPENHO DE MISTURAS ASFÁLTICAS
}

\section{Application of the copper mining residue to improve the performance of asphalt mixtures}

\section{Ricardo Bentes Kato'}

Recebido em 26 de março de 2017; recebido para revisão em 14 de junho de 2017; aceito em 29 de julho de 2017; disponível on-line em 25 de agosto de 2017.

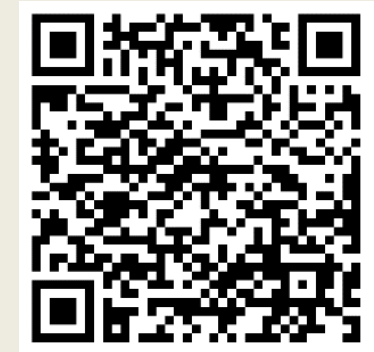

PALAVRAS CHAVE:

Material asfáltico;

Meio ambiente;

Pavimentação;

Resíduo;

Mineração.

\section{KEYWORDS:}

Asphaltic material;

Environment;

Paving;

Resudue;

Mining.

* Contato com o autor:

RESUMO: O presente artigo tem o objetivo de verificar o desempenho de misturas asfálticas frente as propriedades Marshall, quando adicionado resíduo da mineração do cobre em sua composição. Justifica-se este trabalho pela crescente geração de resíduos proveniente da atividade mineração, juntamente com deficiencia da malha rodoviária brasileira. Após caracterização dos materiais e dosagem pelo método Marshall, gradativamente substitui-se a areia do concreto betuminoso usinado à quente pelo rejeito de cobre, onde notou-se uma significativa redução do teor de cimento asfáltico, fato este devido às características granulométricas do rejeito que possibilitou maior fechamento dos vazios na massa. Estes resultados apontam para um potencial uso deste resíduo, com contribuições de ordem ambiental, econômica (pois o CAP responde por considerável parcela do custo do concreto asfáltico) e tecnológicas, pela melhoria dos parâmetros Marshall.

ABSTRACT: The aim of this paper is to verify the performance of asphalt mixtures against Marshall properties when copper mining residue is added in its composition. This work is justified by the growing generation of waste from the mining activity, together with deficiency of the Brazilian road network. After characterization of the materials and dosage by the Marshall method, the sand of bituminous concrete machined by copper refuse was gradually replaced, where a significant reduction of asphalt cement content was observed, due to the granulometric characteristics of the tailings Greater closure of voids in mass. These results point to a potential use of this residue, with contributions of environmental, economic (because the CAP accounts for a considerable portion of the cost of asphalt concrete) and technological, by the improvement of Marshall parameters.

${ }^{1}$ e-mail: r.kato@hotmail.com (R. B. Kato )

Doutor em Engenharia, Professor do Curso de Engenharia Civil do Instituto Tecnológico (ITEC) da Universidade Federal do Paraná (UFPA). 


\section{INTRODUÇÃO}

A mineração é uma das atividades mais antigas da humanidade, com a revolução industrial houve uma crescente demanda por minério para alimenta a indústria. Nesta atividade há um grande inconveniente ambiental que é a geração de resíduos. Estes quando não são reintroduzidos em outro processo produtivo é estocado em bacias de contenção, que além de proporcionar altíssimos custos de construção e manutenção, permanece latente o risco de rompimento e desastres ambientais.

Paralelamente a esta questão ambiental tem-se a importância do transporte para a sociedade, seja sua função econômica ou social. Em qualquer sociedade os transportes têm papel fundamental no desenvolvimento econômico, seja na movimentação de pessoas, seja no transporte de mercadorias, integrando regiões produtivas diferentes, seja no território nacional ou além das fronteiras do país. Analisando financeiramente o custo do transporte contribui positivamente ou negativamente no custo final do produto, por motivos como: o modal escolhido, as taxas cobradas pelo setor até as condições de infraestrutura oferecidas (CALABREZI, 2005).

A literatura mostra que vários resíduos provenientes de processos industriais têm sido utilizados na produção de materiais para a construção civil, mais especificamente para pavimentação, destacando-se: Resíduo quartzito foliado, Fíleres minerais, Resíduo de óleo de xisto, areia de fundição, escória ferro-níquel e borracha de pneu (KIM, et al. 2003; FAXINA, 2006; ALECRIN, 2009; BARDINI et. al., 2012; KLINSKY et al. 2014; ZHANG e HU, 2015).

A oferta de infraestrutura de transporte está intimamente ligada ao processo de desenvolvimento social e econômico, e deve fazer parte dos planos e objetivos de desenvolvimento de cada nação. Neste contexto supracitado encontrase o modal rodoviário. No Brasil este meio responde por cerca de $60 \%$ da matriz brasileira, por onde escoa a produção de bens e serviços (CNT, 2011).

$\mathrm{O}$ principal material utilizado em pavimentação das rodovias brasileira é o concreto betuminoso, que pode ser definido como uma mistura de materiais granulares, material de enchimento, um ligante asfáltico em proporções pré-estabelecidas, onde o ligante atua como elemento aglutinante entre os agregados, permitindo que resista às solicitações de tráfego, onde ao final gera um material composto por três fases: agregado, ligante e ar (PATRIOTA 2004).

Os ligantes asfálticos são uns dos materiais mais antigos utilizados pela humanidade, onde estudos apontam para datas da ordem de 8.000 anos atrás com registro de utilização, onde os assírios já empregavam em seus palácios, empregou-se também o betume na torre de Babel, e relatos bíblicos apontam que Noé calafetou sua arca com esse material. Suas primeiras aplicações foram com argamassas, material para calafetagem de navios e impermeabilizantes. Como material de pavimentação registros datam o ano de 1829 em Lyon na França, utilizado para melhoria das condições de rodagem (MANUAL DO ASFALTO, 1989).

Os Materiais betuminosos são mais do que um único produto, e sim uma variada família de produtos oriunda de tratamentos específicos, onde se caracterizam por serem materiais aglutinantes de cor escura, constituídos de associações de hidrocarbonetos solúveis em bissulfeto de carbono.

Uns dos principais utilizados em pavimentação os CAPs, asfaltos diluídos e emulsionados. O teor de asfalto varia com a intensidade de tráfego, onde em vias de tráfego pesado o mesmo deve ser minimizado, com o intuito de evitar a exsudação provocada pela combinação da densificação da mistura e altas temperaturas (MUGAYAR, 2004).

O CAP é proveniente do produto final da destilação do petróleo cru, do qual frações mais leves (gasolina, querosene e diesel) são separadas do asfalto por vaporização, fracionamento e condensação (IBP, 1999).

O cimento asfáltico pode ser considerado um material visco-elástico, pois a temperaturas baixas pode ser considerado um comportamento elástico, e para altas temperaturas um 
comportamento viscoso, este comportamento se deve a suas características reológicas, onde as forças de ligações fracas entre os átomos deixa o material sensível a temperatura e ao cisalhamento.

$\mathrm{O}$ agregado mineral utilizado em misturas betuminosas tem grande influência nas propriedades futuras da mesma, visto que ocupa entre $88 \%$ e $96 \%$ em peso e $75 \%$ do volume, e são responsáveis pela estrutura sólida que irá resistir às solicitações das caras proveniente do tráfego. A propriedade das misturas é afetada pela graduação dos agregados, relação de vazios, teor de asfalto e tipo de fíller. Por exemplo o aumento do tamanho dos agregados causa profundas alterações nos ensaios de fluência, tração e resiliência da mistura, assim como na deformação permanente que é aumentada sua resistência, quando ensaiada com agregados maiores.

A textura e forma é outro fator preponderante para as características finais da mistura, visto que influencia diretamente da adesão do ligante à superfície do agregado. Vasconcelos (2004) verificou que agregados bem distribuídos granulometricamente proporcionaram maior vida de fadiga ao pavimento, pela melhor compactação do promovida durante a execução do serviço de pavimentação.

Faixas granulométricas mais finas segundo a DNER-ES-031/06 provocam deformações menores do que, logo a faixa " $C$ " possui desempenho melhor do que a " $B$ " e a " $A$ ", porém proporciona maior consumo de ligante, devido sua maior superfície específica para cobrir.

No cenário descrito acima coloca-se o objetivo deste artigo como analisar o teor de cimento asfáltico de petróleo ótimo quando adicionado rejeito da mineração do cobre ao concreto asfáltico usinado à quente. Para se atingir este objetivo será realizada a caracterização dos materiais, procedendo posteriormente a dosagem Marshall preconizada pelo DNIT (Departamento Nacional de Infraestrutura de Transporte).

\section{MATERIAL E MÉTODO}

Para desenvolvimento da pesquisa de avaliação do desempenho do concreto asfáltico frente a adição de resíduo de cobre sulfetado, inicialmente foi realizada a caracterização dos materiais empregados na fabricação dos corpos de prova (seixo rolado de rio e areia de cava) e o rejeito de cobre seguindo a normatização brasileira no Quadro 1.

A areia utilizada na confecção dos corpos de prova utilizados nesta pesquisa é procedente da jazida de Nova Timboteua e caracterizou-se como uma areia fina, o seixo proveniente da jazida Ourém e também com um seixo fino. Já rejeito caracterizou-se como um agregado miúdo muito fino, com um ponto atraente para a mistura asfáltica que foi o teor de material passante na peneira 200 com $16,07 \%$, o que pode funcionar como fíler na massa asfáltica, visto que a areia em questão apresenta apenas $1,80 \%$ de material passante na peneira 200, conforme curvas granulométricas representadas nas Figuras 1, 2 e 3, assim como a Tabela 1 de resumo dos resultados da caracterização.

QUADRO 1: Normas para caracterização dos agregados.

\begin{tabular}{|l|l|}
\hline \multicolumn{1}{|c|}{ Ensaio } & \multicolumn{1}{c|}{ Norma } \\
\hline Dimensão Máx. Característica & DNER-ME 083/1998 \\
\hline Módulo de Finura & DNER-ME 083/1998 \\
\hline Teor Material Pulverulento & DNER-ME 266/1997 \\
\hline Equivalente de Areia & DNER-ME 54/1997 \\
\hline Massa Específica & $\begin{array}{l}\text { DNER-ME 195/1997 } \\
\text { DNER-ME 84/1995 }\end{array}$ \\
\hline
\end{tabular}

FONTE: Normas DNIT. 


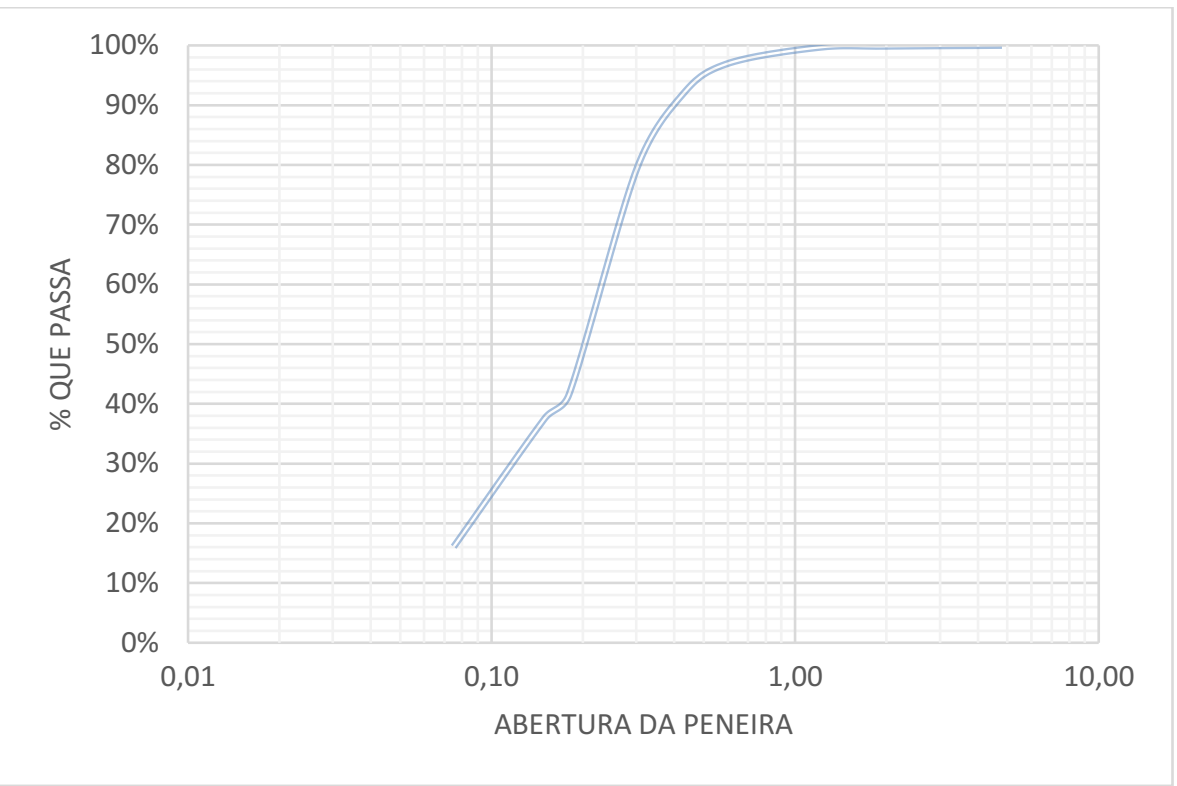

FIGURA 1: Resultado do Ensaio de Granulometria do Resíduo de cobre.

FONTE: Dados da Pesquisa.

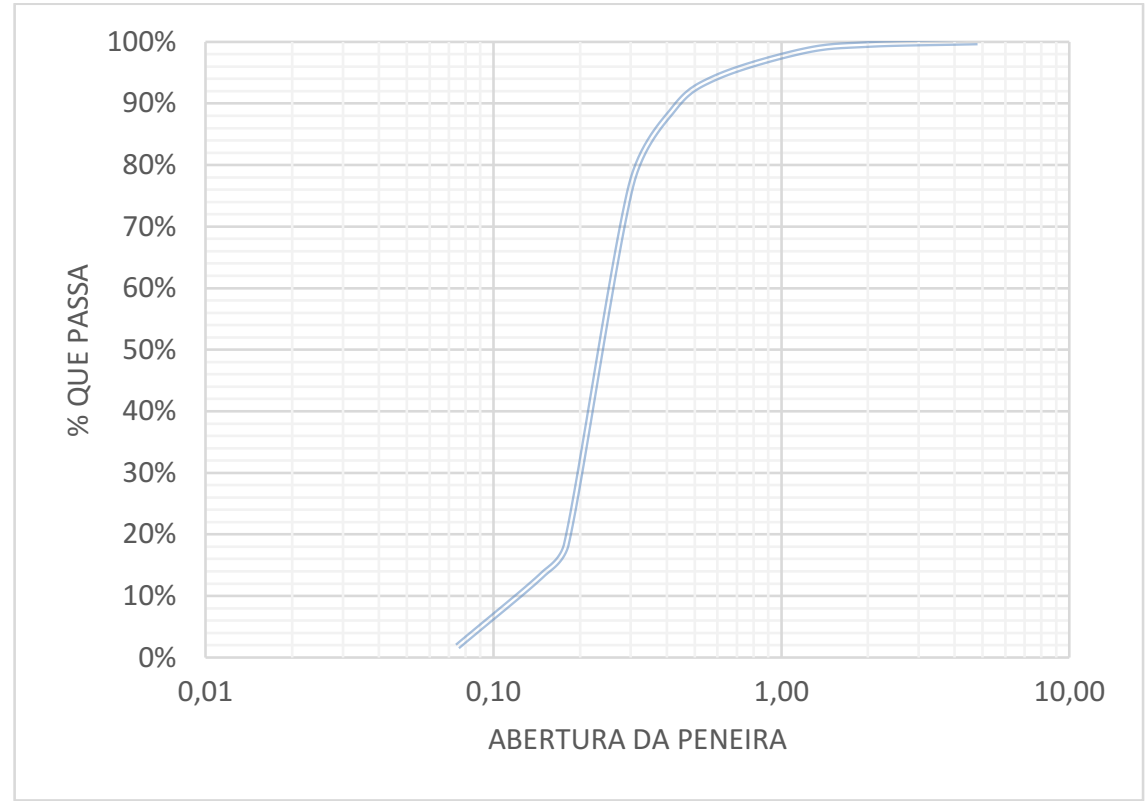

FIGURA 2: Resultado do Ensaio de Granulometria do Areia.

FONTE: Dados da Pesquisa. 


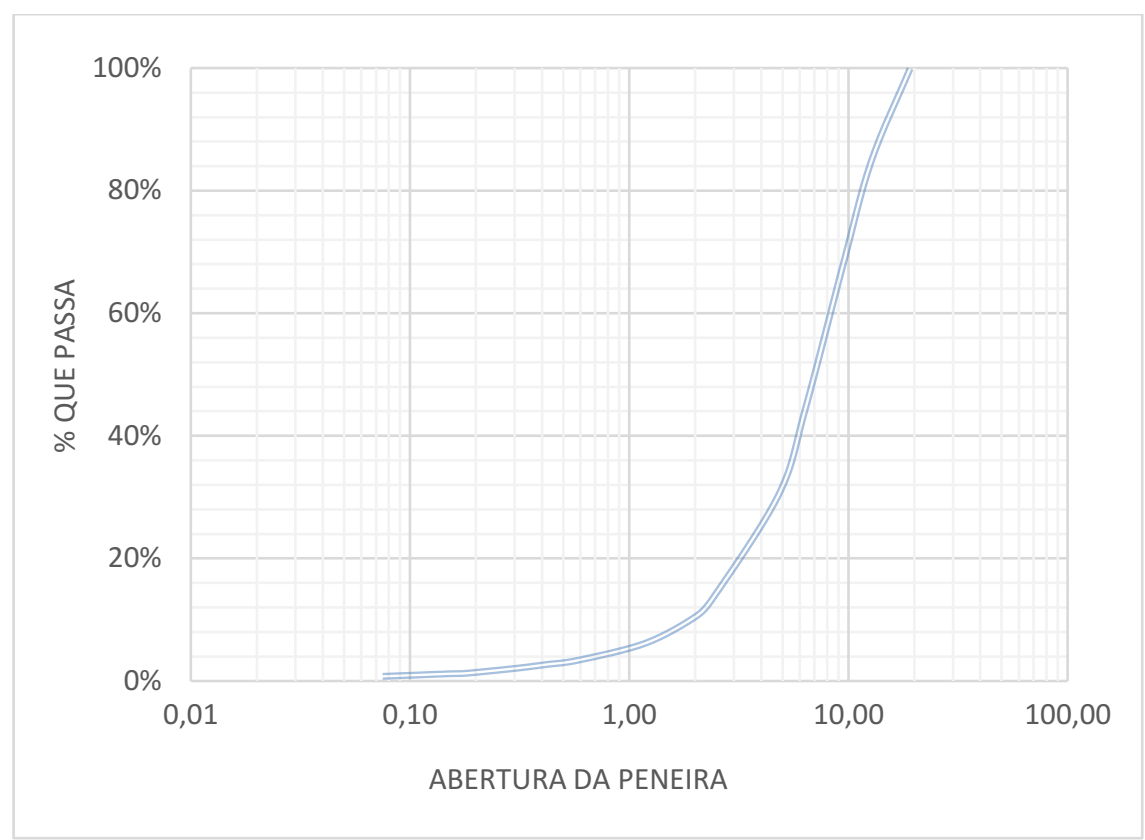

FIGURA 3: Resultado do Ensaio de Granulometria do Seixo.

FONTE: Dados da Pesquisa.

TABELA 1: Resumo da caracterização dos agregados e resíduo.

\begin{tabular}{cccc} 
Ensaio & Seixo & Areia & Resíduo \\
\hline Dimensão Máx. Característica & $19,10 \mathrm{~mm}$ & $1,19 \mathrm{~mm}$ & $0,59 \mathrm{~mm}$ \\
\hline Módulo de Finura & 1,18 & 0,31 & 0,24 \\
\hline Teor Material Pulverulento & $0,70 \%$ & $1,47 \%$ & $9,72 \%$ \\
\hline Equivalente de Areia & - & $97,32 \%$ & $75,68 \%$ \\
\hline Massa Específica & 2,499 & 2,644 & 2,861 \\
\hline
\end{tabular}

FONTE: Dados da pesquisa.

Após caracterização dos agregados e enquadramento na curva granulométrica " $\mathrm{C}$ " do DNIT, ficou estabelecido como dosagem piloto, ou amostra branca, a composição de $75 \%$ de seixo e $25 \%$ de areia. Como definido na metodologia foi procedido a substituição gradativa da areia por rejeito, originando mais 3 dosagens: com $10 \%$ de rejeito, com $20 \%$ de rejeito e com $25 \%$ de rejeito.

O CAP utilizado foi o de referencia 50/70 conforme classificação do DNIT, e com o objetivo de caracterizar o CAP utilizado, assim como definir a temperatura de mistura e compactação foi realizado o ensaio Saybolt-Furol para determinação da temperatura de dosagem e compactação, ficando definido a temperatura de mistura de $141,88^{\circ} \mathrm{C}$ à $161,33^{\circ} \mathrm{C}$ e temperatura de compactação de $140,59^{\circ} \mathrm{C}$ à $148,36^{\circ} \mathrm{C}$, com coeficiente de correlação de 0,9348 , conforme Figura 4.
Com a caracterização executada foi procedida a dosagem, dentro da curva " $\mathrm{C}$ " do DNIT, posteriormente moldados os 15 corpos de prova ( 3 para cada 5 teores de CAP). Dosados os corpos de prova serão realizados e calculados os parâmetros Marshall e definidos os teores de CAP ótimo. Após a dosagem piloto, a areia será substituída gradativamente por rejeito de cobre até a mistura ser totalmente isenta de areia e substituída por cobre conforme descrito na Tabela 2.

Após as dosagens serão analisados os parâmetros Marshall, principalmente com relação a porcentagem de vazios, sendo este o principal parâmetro para a dosagem de misturas asfálticas, juntamente com sua estabilidade e resistência a tração, seguindo os parâmetros do DNIT (Departamento de Infraestrutura de Transportes) apresentados na Tabela 3. 
TABELA 2: Quantidade e teores de rejeito por corpo de prova.

\begin{tabular}{cc} 
DOSAGEM & QUANT. DE CP's \\
\hline Piloto (75\% de seixo $+25 \%$ areia) & 15 \\
\hline $10 \%$ Rejeito (75\% de seixo $+15 \%$ areia $+10 \%$ de rejeito) & 15 \\
\hline $20 \%$ Rejeito (75\% de seixo $+5 \%$ areia $+50 \%$ de rejeito) & 15 \\
\hline $25 \%$ Rejeito (75\% de seixo + $25 \%$ de rejeito) & 15 \\
\hline TOTAL DE CP's & $\mathbf{6 0}$ \\
\hline
\end{tabular}

FONTE: Dados da Pesquisa.

\begin{tabular}{ccc}
\multicolumn{2}{c}{ TABELA 3: } & Parâmetros Marshall. \\
\hline Parâmetros Marshall & Método de Ensaio & Camada de Rolamento \\
\hline Porcentagem de Vazios & DNER-ME 043 & 3 a 5 \\
\hline Estabilidade Mínima (Kgf) (75 golpes) & DNER-ME 043 & 500 \\
\hline
\end{tabular}

FONTE: DNIT031/2006 ES.

Os dados discutidos no item a seguir foram tratados estatisticamente por técnicas de regressão e correlação, para consolidar as conclusões tiradas com respeito ao uso do resíduo em concretos asfálticos usinados a quente.

\section{RESULTADOS E DISCUSSÕES}

Definidas as dosagens de cada mistura, assim como as temperaturas de mistura e compactação foram confeccionados 60 corpos de prova para proceder os parâmetros Marshall e assim definir o teor ótimo de CAP de cada composição (Piloto, $10 \%$ de rejeito, $20 \%$ de rejeito e $25 \%$ de rejeito).

Conforme os requisitos normativos do DNIT ES 031/2006 a estabilidade mínima deve ser de 500 Kgf. Este parâmetro foi superado nas misturas dosadas, com superior desempenho nas misturas com adição de rejeito. Este efeito se deve a presença do material com ação de fíller no resíduo, preenchendo os vazios da massa aumentando então a resistência da mistura, como é possível ser observado na Figura 5.

$O$ volume de vazios pode influenciar a resistência, além de promover aumento da durabilidade por dificultar a entrada de agentes agressivos na massa. O DNIT 031/2006 define um limite entre $3 \%$ e $5 \%$, nota-se que o teor de $10 \%$ de rejeito na massa apresentou o comportamento mais intenso na redução dos vazios da massa, conforme Figura 6. Isso se deve ao fechamento da massa provocada pela granulometria dos componentes da mistura.

Após a determinação dos parâmetros Marshall, foi definido o teor de vazios de $4 \%$ como alvo da mistura, pois este proporciona uma mistura ao mesmo tempo uniforme e maleável às solicitações de tráfego. Para $4 \%$ de vazios está atendida a estabilidade, segundo figura 6 e demais parâmetros, logo pôde-se relacionar o teor de CAP para o teor de vazios indicado pela técnica de regressão e assim traçar o gráfico da Figura 7, onde definiu-se o teor ótimo de resíduo para o menor consumo de CAP, que no caso $7,73 \%$ de rejeito e um consumo de $5,65 \%$ de CAP. 


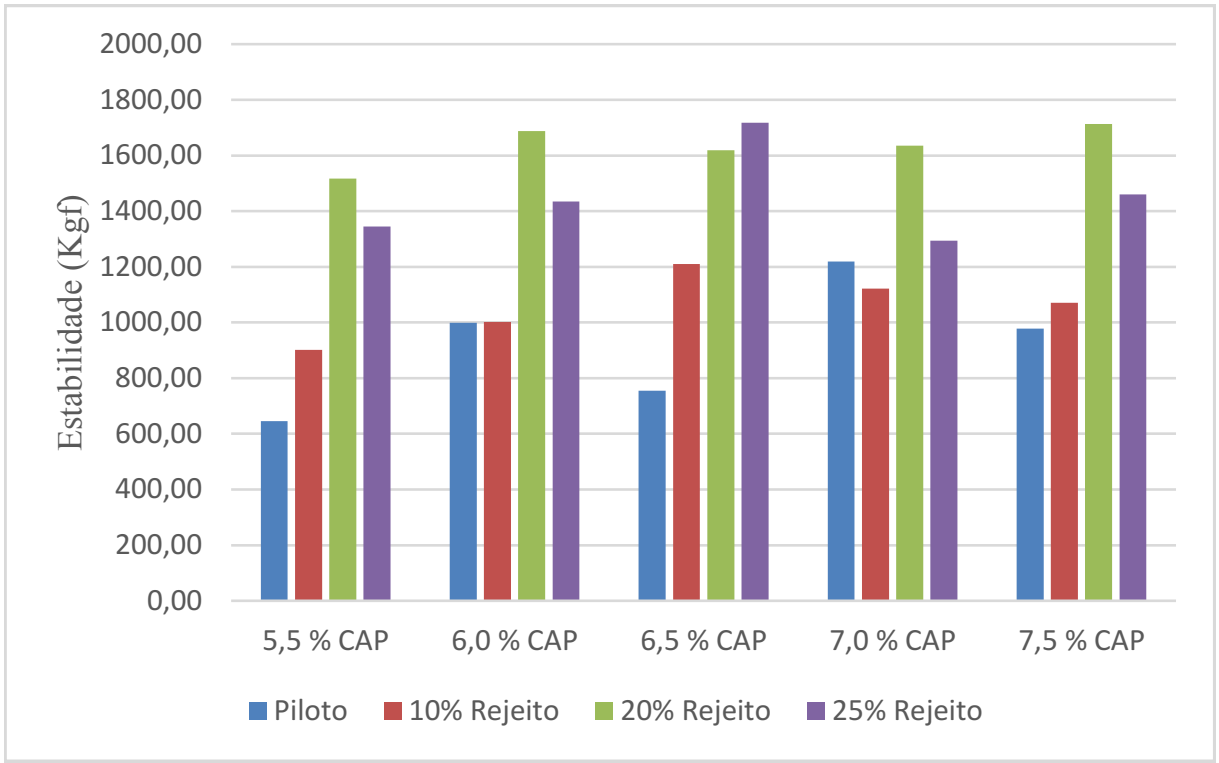

FIGURA 5: Resultados do Ensaio de Estabilidade. FONTE: Dados da Pesquisa.

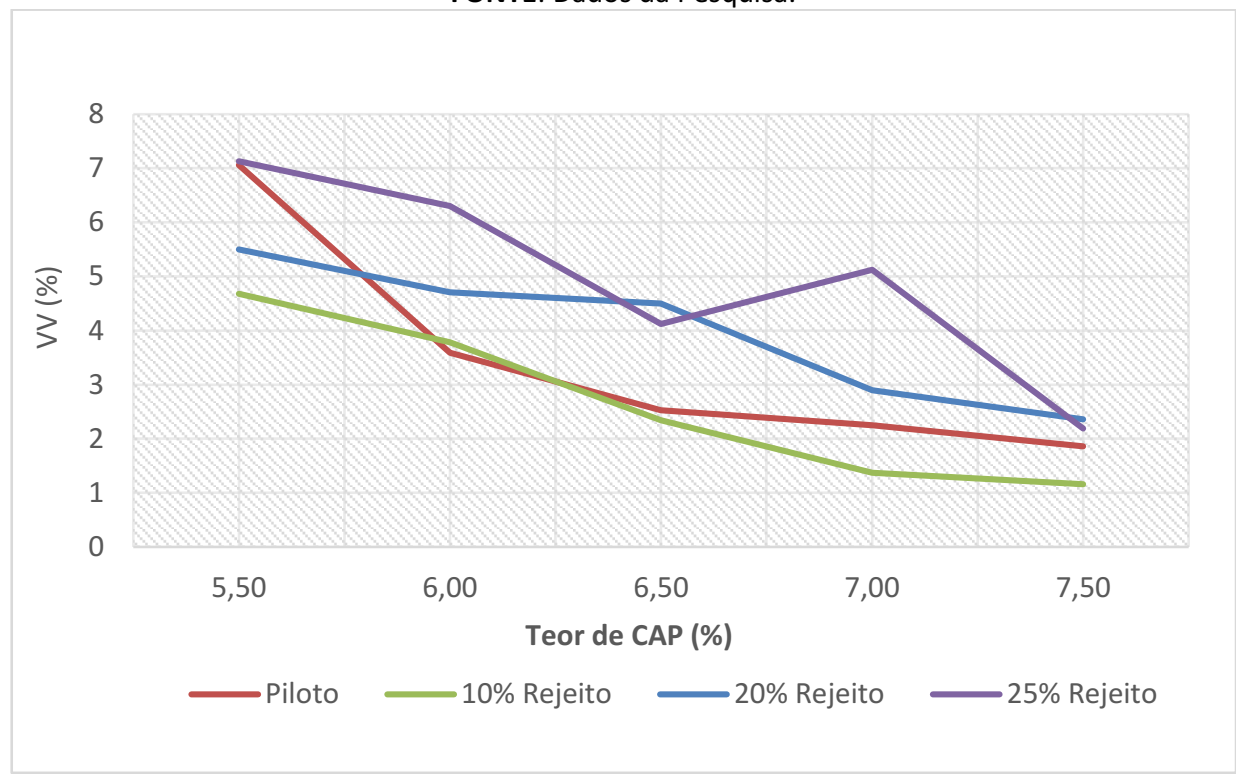

FIGURA 6: Resultados do Ensaio de Volume de Vazios.

FONTE: Dados da Pesquisa.

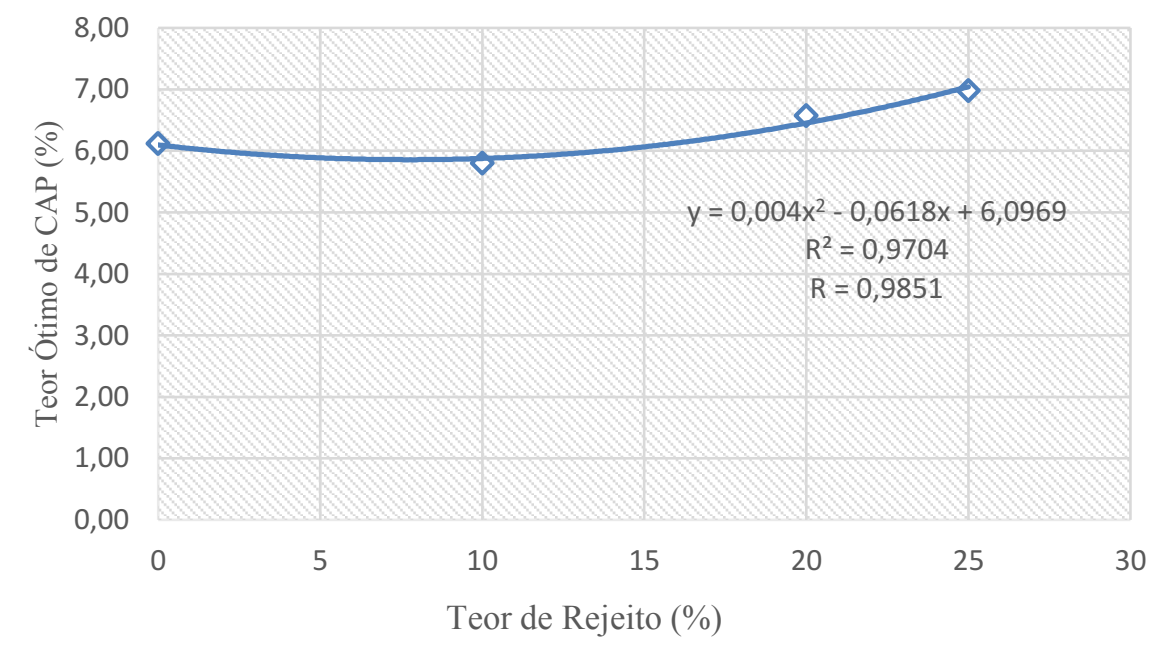

FIGURA 7: Gráfico de Correlação e Regressão entre o teor de resíduo e o teor de CAP FONTE: Dados da Pesquisa. 


\section{CONCLUSÕES}

Conforme descrito anteriormente a adição de rejeito comprovou a hipótese do trabalho pois melhorou todas as características Marshall da mistura, tendo singular importância a redução do teor de CAP (Cimento Asfáltico de Petróleo), o que pode ser dado crédito a suas características granulométricas, contribuindo para um maior fechamento dos vazios, fato este que além de proporcionar maior resistência à massa, aumenta também sua durabilidade por dificultar a penetração de agentes agressivos.

A redução do teor de CAP foi em torno de $8 \%$, quando compara-se a dosagem sem resíduo com a dosagem ótima com 7,73\% de resíduo. Logo, conclui-se que a adição do resíduo na mistura asfáltica traz três benefícios imediatos: Benefício tecnológico (redução do teor de vazios), benefício ambiental (consumo do resíduo gerado pela mineração) e benefício econômico (redução do teor de CAP nas misturas asfálticas).

A pesquisa comprovou o potencial de utilização de resíduo proveniente da mineração de cobre sulfetado, não esgotando os estudos necessários a sua utilização plena, principalmente estudos de fadiga e envelhecimento, porém este estudo contribuiu para a ampliação de mais um campo de aplicação de subprodutos da mineração em materiais de construção, aliando os aspectos ambientais aos técnicos e econômicos.

\section{REFERÊNCIAS BIBLIOGRÁFICAS}

ALECRIM, Adson Viana. Estudo do resíduo quartzito foliado para emprego em estrutura de pavimentos. Dissertação de Mestrado. Escola de Engenharia de São Carlos, SP. 2009.

BARDINI, V. S., KLINSKY, L. M., \& FERNANDES JR, J. L.; ROQUE, R (2012). A influencia do fíler mineral no comportamento reológico de mastiques asfálticos. Revista Transportes. v. 20, n. 3, 2012. Pag. 19-26.

CALABREZI, S. R. A multimodalidade para o transporte de cargas: identificação de problemas em terminais visando à integração dos modais aéreo e rodoviário. Campinas, 2005. [Dissertação]. Campinas: Universidade Estadual de Campinas, Faculdade de Engenharia Civil, Arquitetura e Urbanismo; 2005.
CNT - Confederação Nacional dos Transportes. Pesquisa CNT de Ferrovias 2011. Brasília: CNT, 2011.

DEPARTAMENTO NACIONAL DE ESTRADAS E RODAGENS (1995). ME - 043/95: Agregados - Análise granulométrica. Rio de Janeiro.

DEPARTAMENTO NACIONAL DE ESTRADAS E RODAGENS (1997). ME - 54/97: Agregados - Equivalente de Areia. Rio de Janeiro.

DEPARTAMENTO NACIONAL DE ESTRADAS E RODAGENS (1997). ME - 266/97: Agregados - Material Pulverulento. Rio de Janeiro.

DEPARTAMENTO NACIONAL DE ESTRADAS E RODAGENS (1994). ME - 117/94. Misturas Betuminosas Determinação da Densidade Aparente.

DEPARTAMENTO NACIONAL DE ESTRADAS E RODAGENS (1995). ME - 043/95: Misturas Betuminosas à quente. Rio de Janeiro.

DEPARTAMENTO NACIONAL DE INFRAESTRUTURA DE TRANSPORTE (2006). ES 31/2006: Pavimentos Flexíveis Concreto Asfáltico. Rio de Janeiro.

DEPARTAMENTO NACIONAL DE PRODUÇÃO MINERAL. Informe Mineral. Janeiro/Julho 2014. Brasília.

FAXINA, Alberto Leandro. Estudo da viabilidade técnica do uso de resíduo de óleo de xisto como óleo extensor de ligantes asfálto-borracha. Tese de Doutorado. Escola de Engenharia de São Carlos, SP. 2006.

IBP. Informações Básicas sobre Materiais Asfálticos. 7ạ Edição. IBP/Comissão do asfalto. Rio de Janeiro, 1999.

KIM, Y. R., LITTLE, D. N., \& SONG, I. I. (2003). Effect of Mineral Fillers on Fatigue Resistances and Fundamental Material Characteristics: Mechanistic Evaluation.. Transportation Research Record: Journal of the Transportation Research Board, 1832, 1-8.

KLINSKY, L. M.; BARDINI, V. S.; FABBRI, G. T. Efeito da adição de areia de fundição residual e cal a solos argilosos no módulo de resiliência. Revista Transportes. v. 22, n. 2, 2014. Pag 1-10

LEITE, L.F.M. Estudo de preparo e caracterização por polímeros. Tese de [Doutorado]. Rio de Janeiro: COPPE/UFRJ; 1999.

MUGAYAR, A. N. Avaliação dos efeitos do tipo de asfalto e da distribuição granulométrica do agregado na fluência estática e dinâmica de misturas asfálticas densas. [Dissertação]. São Carlos: USP - Universidade de São Paulo; 2004.

INSTITUTO DO ASFALTO. Manual do Asfalto. Série N 04 (MS-4), 1989. 
PATRIOTA. Análise laboratorial de concreto betuminoso usinado à quente modificado com borracha reciclada de pneus - processo seco. [Dissertação]. Recife: Universidade Federal de Pernambuco; 2004.

SANTOS, Graziella Pereira Pires dos. Um Estudo Sobre a Utilização da Escória de Ferroníquel em Pavimentação Rodoviária. Dissertação de Mestrado. Instituto Militar de Engenharia, RJ. 2013. 124 p.

ZHANG, F., \& HU, C. (2015). "The Research for Structural Characteristics and Modification Mechanism of Crumb Rubber Compound Modified Asphalt". Construction and Building Materials, 76, 330-342. 